\title{
Culture Parameters Affect the Light Emitting Property of Organisms Isolated from Two Marine Fishes
}

\author{
Anuradha Pandey Dubey and Madhuri Sharon* \\ Walchand Centre for Research in Nanotechnology and Bionanotechnology, \\ WCAS, Solapur, Maharashtra India \\ *Corresponding Author: Madhuri Sharon, Walchand Centre for Research in \\ Nanotechnology and Bionanotechnology, WCAS, Solapur, Maharashtra India.
}

Received: March 04, 2020

Published: April 16, 2020

(C) All rights are reserved by Anuradha

Pandey Dubey and Madhuri Sharon.

\begin{abstract}
Organisms were isolated and cultured from two marine fishes (Stolephorus indicus and Nemipterus japonicus) that were exhibiting Bioluminescence. Identification and assessment of impact of five different culture media on the growth and light emission properties were studied. Isolates from both the fishes showed microbes to be gram negative Coccobacilli, Partial gene sequencing analysis suggested that the microbes belonged to Vibrio spp and Photobacterium spp. Biochemical analysis of both the bacterial isolates exhibited difference in sugar (Mannitol and Lactose), LDC, Indole and Urea content; suggesting that the two isolated colonies are different bioluminescent bacteria. Repeated subculture (to obtain pure colonies) of both the isolates resulted in gradual reduction in the intensity of luminescence of the bacteria and eventually loss of luminescence property occurred. However, luminescence was revived when they were grown in aerated condition.

Keywords: Bioluminescence; Anchovy Fish; Threadfin Bream Fish; Growth Curve; Lux Operon; Luciferase; Boss Medium
\end{abstract}

\section{Introduction}

Bioluminescence has attracted interest of researchers due to its immense applications in the near future. Bioluminescent organisms are being exploited for their utility as biosensors, biolighting, designing purpose, street lighting, detection of toxic compounds in environment and many more. Bioluminescence is the emission of light produced by microorganisms due to luciferase activity. These microorganisms are found as free living or as gut symbionts in marine environment. They are widely spread in terrestrial environment, fresh water and marine ecosystems.

Bioluminescence is a phenomenon that usually results from biochemical and enzymatic activity of living microorganisms. The reaction involves oxidation of long chain aliphatic aldehyde and reduced flavin mononucleotide (FMNH2) in the presence of enzyme luciferase. It basically involves a group of genes i.e. the lux operon. The lux operon constitutes the genes luxICDABEG. LuxA gene codes for $\alpha$ and LuxB gene codes for $\beta$ subunits. The lux CDE genes are fatty acid reductase genes that codes for polypeptides. It is important and necessary for the conversion of fatty acids into the long chain aldehyde (fatty acid pathway) [1-3]. In the process of bioluminescence, the excess energy is liberated and emitted as a luminescent blue-green light at around $490 \mathrm{~nm}$.
Many attempts have been made by researchers to apply bioluminescent reactions in practice including environmental protection, agriculture, food technology, biosensors and in genetic engineering. It was observed that bioluminescence is a property of certain bacteria found in abundance in marine ecosystems and that the presence of chemical pollutants and toxins disturbs cell metabolism of bioluminescent bacteria, reducing the intensity of the emitted light [Kießling and Rayner-Brandes 1998, BioTox ${ }^{\mathrm{TM}} \ldots$ 1996].

Luminescent bacteria are facultative aerobes. The capacity for bacteria to luminescence is closely related to the composition of the culture medium. In order for the bacteria to generate light the presence and access to oxygen are required. The end product of bacterial luminescence, which is frequently compared to respiration, is not adenosine triphosphate (ATP), but the excited chemical compound emitting light called luciferase. The bacterial luminescence is visible only after it reaches a certain cell density $[2,3]$.

Many aquatic bioluminescent species such as fishes, crabs, jelly fishes etc. found in the marine environment [3,4]. The luminescence is due to the presence of symbiotic bacteria, which thrive on hosts. 
From the scientific point of view advances in the isolation of bioluminescent bacteria as well as the determination of different media for optimal culture conditions and growth are of great importance. This research work mainly focuses on the study of isolated bioluminescent organisms from different sources and assessment of their light emission under different cultural conditions and parameters.

\section{Materials and Methods}

Source of procuring fish

Two marine species of fishes i.e. Threadfin bream (local name Raja Rani fish) and Anchovy fish (local name-Mandeli fish) were procured from the local market.

\begin{tabular}{|c|c|c|}
\hline & Anchovy Fish & Threadfin bream Fish \\
\hline Kingdom & Animalia & Animalia \\
\hline Phylum & Chordata & Chordata \\
\hline Class & Actinopterygii & Actinopterygii \\
\hline Order & Clupeiformes & Perciformes \\
\hline Family & Engraulidae & Nemipteridae \\
\hline Genus & Stolephorus & Nemipterus \\
\hline Species & indicus & Japonicas \\
\hline Habitat & $\begin{array}{l}\text { Widely distrib- } \\
\text { uted throughout the } \\
\text { worlds ocean, mainly } \\
\text { found in temperate } \\
\text { waters, but rarely } \\
\text { observed in cold or } \\
\text { warm seas also. }\end{array}$ & $\begin{array}{l}\text { Mostly found in tropical marine } \\
\text { waters of Indian and western } \\
\text { pacific oceans }\end{array}$ \\
\hline
\end{tabular}

Table 1: Classification of Anchovy and Threadfin bream Marine Fish.
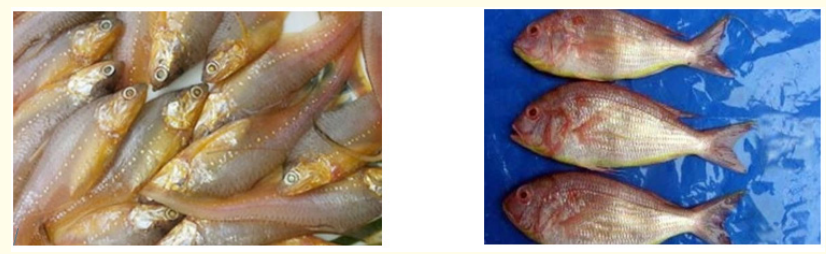

Figure 1: (Left) Anchovy fish (Stolephorus indicus) local name is Mandeli and (Right) Threadfin bream fish (Nemipterus japonicus) locally known as Rani fish; collected from local market.

\section{Isolation of bioluminescent bacteria}

Fishes collected from local market were used for isolation of bioluminescent bacteria using five different media. The bacterial suspensions were prepared by scraping the surface of the fishesAnchovy fish and threadfin bream fish using normal saline. This suspension was primarily used for isolation using the T- streak method and side streak method. The plates were incubated at room temperature $25^{\circ} \mathrm{C} \pm 2{ }^{\circ} \mathrm{C}$ for 24 hours. After 24 hours the plates were observed in dark room for isolated colonies that showed bioluminescence $[5,6]$. The bioluminescent colonies were then picked up and further subcultured several times on agar plate in order to obtain only bioluminescent colonies without any contamination.

\section{Culture media used}

Five different culture media were tried to isolate and culture Bioluminescent organisms from both the fishes (Table 2); they were - BOSS medium, LA medium, Photobacterium medium, LM medium and NCBE medium $[3,10]$.

\section{Observations}

Morphological characterization, growth curve study, biochemical analysis of isolated bacteria and light emission by isolated microbes were recorded.

The microscopic characterization of the isolated bioluminescent bacteria was done to record its morphology i.e. shape (cocci, bacilli, rod etc.), size, consistency, colour and elevation. Gram staining was carried out to distinguish gram positive and gram negative bacteria

Growth curve study of the isolates was carried out using 24 hours old culture. For growth curve study Boss medium was used. $25 \mathrm{ml}$ of the medium was sterilized in a side arm flask and used for further studies. The optical density (OD) values were checked at regular intervals to observe the growth pattern of the isolates.

Moreover, standard biochemical content was also analyzed. The bioluminescent bacteria were successfully isolated from Anchovy and threadfin bream fish thriving in the marine waters of Mumbai. The isolates were labelled as isolate 1 and isolate 2 respectively. The biochemical analyses were done to differentiate between the two isolates.

Luminescence of microbial cultures growing on slants and petri plates were recorded.

\section{Results}

The growth curve of bacterial isolate from Anchovy fish and from Threadfin bream fish is presented in figure 2 . The black line represents the normal growth curve of luminescence bacteria. The log phase of growth was recorded to be for 3 hours after subculture, whereas the green line represents the luminescence of the bacteria which takes place in the log phase. Both isolates exhibited similar growth curve pattern. 


\begin{tabular}{|c|c|c|c|c|}
\hline Boss medium & LA medium & Photobacterium medium & LM medium & NCBE medium \\
\hline $\mathrm{NaCl}-30 \mathrm{~g}$ & $\mathrm{NaCl}-10 \mathrm{~g}$ & NaCl- $30.0 \mathrm{~g}$ & $\mathrm{CaCO}_{3}-1 \mathrm{~g}$ & Yeast extract- $3 g$ \\
\hline Glycerol-1g & Yeast extract- $5 \mathrm{~g}$ & $\mathrm{NH}_{4} \mathrm{Cl}-0.30 \mathrm{~g}$ & Glycerol- 3g & Bacto-peptone- $5 g$ \\
\hline Bacto-peptone- $10 \mathrm{~g}$ & Bacto-peptone- $10 \mathrm{~g}$ & $\mathrm{MgSO}_{4}-0.30 \mathrm{~g}$ & Yeast extract- $3 g$ & Distilled water $-250 \mathrm{ml}$ \\
\hline Meat extract $-3 g$ & Agar-15g & $\mathrm{FeCl}_{3}-0.01 \mathrm{~g}$ & Tryptone- 3g & Sea water $-750 \mathrm{ml}$ \\
\hline \multirow[t]{6}{*}{$\begin{array}{l}\text { Made up to } 1000 \mathrm{ml} \\
\text { with distilled water }\end{array}$} & \multirow{6}{*}{$\begin{array}{l}\text { Made up to } 1000 \mathrm{ml} \\
\text { with distilled water }\end{array}$} & $\mathrm{CaCO}_{3}-1.00 \mathrm{~g}$ & \multirow{6}{*}{$\begin{array}{l}\text { Made up to } 1000 \mathrm{ml} \\
\text { with sea water }\end{array}$} & \\
\hline & & $\mathrm{KH}_{2} \mathrm{PO}_{4}-3.00 \mathrm{~g}$ & & \\
\hline & & Na glycerophosphate- $23.50 \mathrm{~g}$ & & \\
\hline & & Casein hydrolysate $-5 g$ & & \\
\hline & & Yeast extract- $2.5 \mathrm{~g}$ & & \\
\hline & & Made up to $1000 \mathrm{ml}$ with distilled water & & \\
\hline
\end{tabular}

Table 2: Media composition.

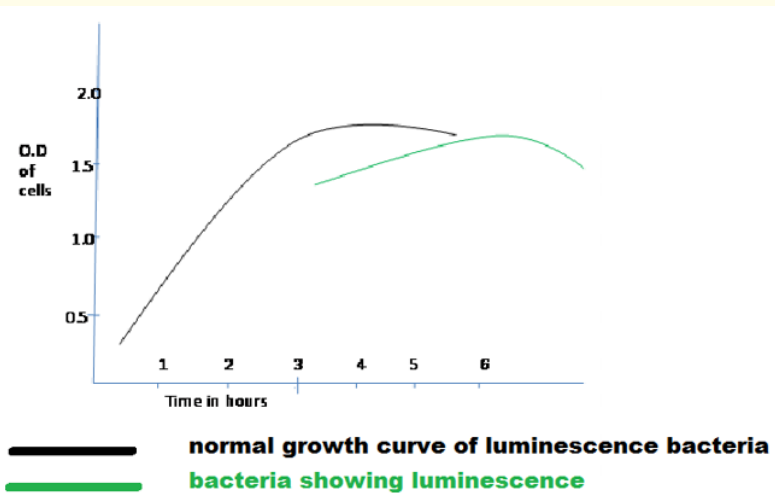

Figure 2: Growth curve pattern exhibited by both isolate 1 and isolate 2 .

\begin{tabular}{|l|c|c|}
\hline \multicolumn{1}{|c|}{ Biochemicals } & Isolate 1 & Isolate 2 \\
\hline Xylose & -ve & -ve \\
\hline Mannitol* & -ve & +ve \\
\hline Glucose & +ve & +ve \\
\hline Lactose* & -ve & +ve \\
\hline Maltose & +ve & +ve \\
\hline Sucrose & +ve & +ve \\
\hline LDC* & -ve & +ve \\
\hline ODC & -ve & -ve \\
\hline TSI & -ve & -ve \\
\hline Indole* & -ve & +ve \\
\hline MR & +ve & +ve \\
\hline VP & +ve & +ve \\
\hline Urea* & -ve & +ve \\
\hline
\end{tabular}

Table 3: Biochemical analysis of isolates 1and 2 taken from 2 fishes. *: Biochemical analysis of organisms provides us the information regarding their differing metabolism thus differentiating their types. It mainly comprises of sugar utilization test, protein utilization and their detection based upon the end products.
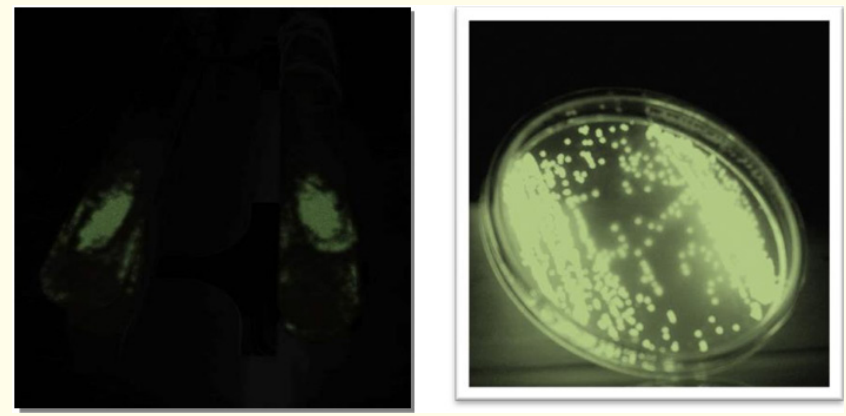

Figure 3: Light Emission by Isolated Microbes cultures on slant as well as petridish.

Both the isolates were found to be gram negative Coccobacilli. The two isolates 1 and 2 were found to differ in the sugar utilization (Table 3) which proves that the two isolated colonies are different bioluminescent bacteria.

The bioluminescent organisms in study showed differences in their carbohydrate metabolism (sugars i.e. mannitol, lactose (Table 3) and the utilization of amino acid tryptophan which was detected by the production of indole using Kovac's reagent.

The isolates also differ in LDC i.e. lysine decarboxylase test decarboxylases are a group of substrate specific enzymes that are capable of reacting with carboxyl portion of amino acids, forming alkaline reacting amines and by product carbon dioxide, increased $\mathrm{pH}$ of medium is detected by color change. Each carboxylase enzyme is specific for an amino acid. The isolated organisms vary in the conversion of lysine to cadaverine (Table 3). 
Urea is the product of decarboxylation of amino acids. Hydrolysis of urea produces ammonia and $\mathrm{CO} 2$ thus increasing the alkalinity which is detected by color change. The isolates differ in urea test.

The luminescence intensity of bacteria was recorded using BIOTEK imaging reader. The best luminescence recorded was 12940576 which was around 10000 times more as compared to negative or non-luminescent culture. It was found that isolates obtained on BOSS media showed better luminescence as compared to other media (LM, PB, LA and NCBE media). Hence, BOSS media was used for further study. The isolated bacteria were named as isolate 1 and isolate 2 obtained from Anchovy fish and threadfin bream fish respectively. These isolates were repeatedly subcultured to obtain pure colonies. However, after several subcultures the luminescence of the bacteria was found to be reducing; as several subcultures result in the loss of luminescence property.

Several attempts were made to revive the cultures and its bioluminescence property using different medium and conditions. The attempt of reviving the bioluminescence of the culture came to fruition using Photobacterium media. The Photobacterium media consisted of various salts like Sodium chloride, ammonium chloride, magnesium sulphates, ferric chloride and calcium carbonate which enriches the medium and was thought to be aiding the bacteria to luminescent.

To revive the luminescence of the bacterial culture which had lost the luminescence, their growth was carried out in aerated condition. The intensity of luminescence was found to be related to the aeration of the culture. The greater the aeration the greater was the luminescence.

The biochemical studies of the isolates were done for the identification of the bacteria and isolates resembled the characteristics of Vibrio spp and Photobacterium spp. Further molecular studies done by Geneombio laboratories at Baner, Pune confirmed it. The results obtained for partial gene sequencing of both the isolates are described below.

\section{FASTA FORMAT SEQ}

Partial gene sequencing results for isolate obtained from threadfin bream fish (Rani fish)

ACGAGT TAT C TGAAC C T TCGGGGAACGATAACGGCGT C GAGCGGCGGACGGGTGAGTAATGC CTAGGAAATTGCCCTGATGTGGGGGATAACCATTGGAAACGATGGCTAATACCGCATAATGC CTACGGGCCAAAGAGGGGGACCTTCGGGCCTCTCGCGTCAGGATATGCCTAGGTGGGATTAG CTAGTTGGTGAGGTAAGGGCTCACCAAGGC-
GACGATCCCTAGCTGGTCTGAGAGGATGATCA GCCACACTGGAACTGAGACACGGTCCAGACTCCTACGGGAGGCAGCAGTGGGGAATATTGCA CAATGGGCGCAAGCCTGATGCAGCCATGCCGCGTGTGTGAAGAAGGCCTTCGGGTTGTAAAG CACTTTCAGTCGTGAGGAAGGTAGTGTAGTTAATAGCTGCATTATTTGACGTTAGCGACAGA AGAAGCACCGGCTAACTCCGTGCCAGCAGCCGCGGTAATACGGAGGGTGCGAGCGTTAATCG GAATTACTGGGCGTAAAGCGCATGCAGGTGGTTTGTTAAGTCAGATGTGAAAGCCCGGGGCT CAACCTCGGAATTGCATTTGAAACTGGCAGACTAGAGTACTGTAGAGGGGGG

Partial gene sequencing results for isolate obtained from Anchovy (Mandeli fish)

GGGAGGCAGCAGTGGGGAATATTGCACAATGGGCGCAAGCCTGATGCAGCCATGCCGCGTGT GTGAAGAAGGCCTTCGGGTTGTAAAGCACT TTCAGTCGTGAGGAAGGTAGTGTAGTTAATAG CTGCATTACTTGACGTTAGCGACAGAAGAAGCACCGGCTAACTCCGTGCCAGCAGCCGCGGT AATACGGAGGGTGCGAGCGTTAATCGGAATTACTGGGCGTAAAGCGCATGCAGGTGGTTTGT TAAGTCAGATGTGAAAGCCCGGGGCTCAACCTCGGAATAGCATTTGAAACTGGCAGACTAGAGTACTGTAGAGGGGGGTAGAATTICAGGIGTAGOGGTGAAATGCGTAGAGATCTGAAGGAAT ACCGGTGGCGAAGGCGGCCCCCTGGACAGATACTGACACTCAGATGCGAAAGCGTGGGGAGC AAACAGGATTAGATACCCTGGTAGTCCACGCCGTAAACGATGTCTACTTGGAGGTTGTGGCC TTGAGCCGTGGCTTTCGGAGCTAACGCGTTAAGTAGACCGCCTGGGGAGTACGGTCGCAAGA TTAAAACTCAAATGAATTGACGGGGGCCCGCACAAGCGGTGGAGCATGTGGTTTAATTCGAT GCAACGCGAAGAACCTTACCTACTCTTGACATCCAGAGAACTTTCCAGAGATGGATTGGTGC CTTCGGGAACTCTGAGACAGGTGCTGCATGGCTGTCGTCAGCTCGTGTTGTG

The study of bioluminescence from different biosystems provides us with a lot of information on the mechanism of bioluminescence. The property of bioluminescence is exploited in biotechnology, environmental microbiology and various fields to apply it as biosensors, microtox assays etc. on the basis of their light intensities $[5,15]$. Furthermore, the lux gene can be exploited for various genetic studies and as biosensors.

\section{Discussion}

The growth curve pattern shown by both the isolates indicates that as the culture reaches certain density it starts exhibiting luminescence especially in the logarithmic phase and continues to exhibit until the media starts depleting (quorum sensing). After few hours the culture media becomes more turbid due to excessive growth and starts reaching the death phase and impacts the luminescence of bacteria; however if the medium is replenished the luminescence can be maintained. The biochemical characterisation of the isolated shows difference in sugar utilization especially mannitol and lactose. Isolate 1 could not utilize sugars mannitol and 
lactose whereas isolate 2 metabolizes mannitol and lactose. The protein metabolism also differs in both the isolates (Table 3). Isolate 1 was negative for LDC- which means cannot metabolize the amino acid Lysine, INDOLE- indicative of not metabolizing tryptophan into indole and UREA- indicative of not hydrolyzing urea whereas isolate 2 was positive for utilization of lysine decarboxylase, INDOLE and UREA. The difference shown in the biochemical characteristics is indicative that the two isolates are not same.

Furthermore, the molecular characterization results obtained by partial gene sequencing is also indicative of bacterial isolates being different. The study thus reveals the impact of various cultural parameters on the growth of bioluminescent bacteria. However further quantification and detailed analysis is in the process and will be represented in the next research paper [16-31].

\section{Conclusion}

The bioluminescence study, their cultural characteristics growth pattern provides information regarding the effect of repeated subcultures on bioluminescence, revival of luminescence depending on the aeration conditions or oxygen level and various salts that affect the luminescence intensity of bacteria.

\section{Bibliography}

1. Bluth BJ., et al. "Cell-Cell Communication and the lux operon in Vibrio fischeri”, Pittsburgh: Department of Biological Sciences. Carnegie Mellon University (2003).

2. Coval K., et al. "Molecular Biology of Prokaryotes Term Paper Subjects and Teams: Quorum Sensing: Table of Contents" (1999).

3. B Danyluk., et al. "BilskaAn objective Method to Assess Bioluminescent Properties of Selected Bacterial Strains". Acta Scientiarum Polonorum Technologia (2007): 5-16.

4. T Gokhale., et al. "Research of Marine Isolates in Development of Biosensor for environmental Pollutants". Engineering Review 32.1 (2012): 17-22.

5. MW Griffith. "Applications of Bioluminescence in the Dairy Industry". Journal of Dairy Science 76.10 (1993): 3118-3125.

6. M Kannahi and S Sivasankari. "Isolation and Identification of Bioluminescent Bacteria from Marine Water at Nagapattinam Sea Shore Area". International Journal of Pharmaceutical Science Review and Research 59 (2014): 346-351.
7. K Kita-Tsukamoto., et al. "Rapid identification of marine bioluminescent bacteria by amplified $16 \mathrm{~S}$ ribosomal RNA gene restriction analysis". FEMS Microbiology Letters 256 (2006): 298-303.

8. AR Kumar. "Isolation of Luminescent Bacteria from Bay of Bengal and their Molecular Characterization", University of Borås/ School of Engineering (2010).

9. LC Lin and EA Meighen. Bacterial Bioluminescence (2009).

10. J Malave-Orengo., et al. "Isolation and characterization of bioluminescent bacteria from marine environments of Puerto Rico, Current Research, Technology and education Topics in Applied". Microbiology and Microbial Biotechnology (2010): 103-108.

11. EA Meighen and EA Bacterial "Bioluminescence: organization, regulation and application of the lux genes". FASEB Journal 7 (1993): 1016-1022.

12. EA Meighen. "Molecular biology of bacterial bioluminescence". Microbiology Reviews 55.1 (1991): 123.

13. A Nawaz and N Ahmed. "Isolation and Characterization of Indigenous Luminescent Marine Bacteria from Karachi Coast". Academic Research International 1.2 (2011): 74-83.

14. VDS Nunes-Halldorson and NL Duran. "Bioluminescent Bacteria: Lux genes as an environmental biosensors". Brazilian Journal of Microbiology 34 (2003): 91-96.

15. FL Thompson., et al. "The Biology of Vibrios", Washington, ASM Press (2006): 204-218.

16. Warner JA and JF Case. "The zoogeography and dietary induction of bioluminescence in the midshipman fish, Porichthys notatus". The Biological Bulletin 159 (1980): 231-246.

17. Haddock HD. "Bioluminescence in the Sea". Annual Review of Marine Science (2010): 443-493.

18. Labas YA., et al. "On the origin of bioluminescent systems". In Bioluminescence and Chemiluminescence 2000, edition. JF Case, PJ Herring, BH Robison, SHD Haddock, LJ Kricka, PE Stanley (2000): 91-94.

19. Yamaguchi S and Endo K. "Molecular phylogeny of Ostracoda (Crustacea) inferred from 18S ribosomal DNA sequences: implication for its origin and diversification". Marine Biology 143 (2003): 23-38. 
20. Tinn 0 and Oakley T. "Erratic rates of molecular evolution and incongruence of fossil and molecular divergence time estimates in Ostracoda (Crustacea)". Molecular Phylogenetics and Evolution 48 (2008): 157-167.

21. Forey PL and Patterson C. "Description and systematic relationships of Tomognathus, an enigmatic fish from the English Chalk". Journal of Systematic Palaeontology 4 (2006): 157-184.

22. Carnevale G. "Miniature deep-sea hatchetfish (Teleostei: Stomiiformes) from the Miocene of Italy". Geological Magazine 145 (2008): 73.

23. Latz M and Rohr J. "Luminescent response of the red tide dinoflagellate Lingulodinium polyedrum to laminar and turbulent flow". Limnology and Oceanography 44 (1999): 1423-435.

24. Chen AK., et al. "Evidence for the role of G- proteins in flow stimulation of dinoflagellate bioluminescence". American Journal of Physiology Regulatory, Integrative and Comparative Physiology 292 (2007): R2020-R2027.

25. Dassow Peter von., et al. "Bioluminescent response of the dinoflagellate Lingulodinium polyedrum to developing flow: Tuning of sensitivity and the role of desensitization in controlling a defensive behavior of a planktonic cell". Limnology and Oceanography 50.2 (2005): 607-619.

26. Latz M., et al. "Bioluminescent response of individual dinoflagellate cells to hydrodynamic stress measured with millisecond resolution in a microfluidic device". The Journal of Experimental Biology 211 (2008): 2865-2875.

27. Panceri M. "Etudes sur la phosphorescence des animaux marins”. Annales des Sciences Naturelles 16 (1872): 1-67.

28. Mackie GO. "Propagation of bioluminescence in Euphysa japonica hydromedusae, (Tubulariidae)". Hydrobiologia 216 (1991): 581-588.

29. Daunert S and Deo SK. "Photoproteins in Bioanalysis". New York: Wiley-VCH (2006): 256.

30. Bode VC., et al. "Daily rhythm of luciferin activity in Gonyaulax polyedra”. Science 141 (1963): 913-915.

31. Lapointe M and Morse D. "Reassessing the role of a $3^{\prime}$-UTRbinding translational inhibitor in regulation of circadian bioluminescence rhythm in the dinoflagellate Gonyaulax". Journal of Biological Chemistry 389 (2008): 13-19.

\section{Assets from publication with us}

- Prompt Acknowledgement after receiving the article

- Thorough Double blinded peer review

- Rapid Publication

- Issue of Publication Certificate

- High visibility of your Published work

Website: https://www.actascientific.com/

Submit Article: https://www.actascientific.com/submission.php Email us: editor@actascientific.com

Contact us: +919182824667 